\title{
Sintesis Zeolit-A dari Abu Dasar Batubara dengan Pemisahan Fe dan $\mathrm{Ca}$
}

\author{
Randy Yusuf Kurniawan dan Nurul Widiastuti \\ Jurusan Kimia, Fakultas Matematika dan Ilmu Alam, Institut Teknologi Sepuluh Nopember (ITS) \\ Jl. Arief Rahman Hakim, Surabaya 60111 Indonesia \\ e-mail: nurul_widiastuti@chem.its.ac.id
}

\begin{abstract}
Abstrak-Penelitian ini bertujuan untuk mensintesis zeolit-A dari abu dasar dengan pemisahan kandungan $\mathrm{Fe}$ dan Ca sebelum dilakukan peleburan. Zeolit-A disintesis menggunakan ekstrak yang dihasilkan melalui metode peleburan abu dasar pada suhu $7^{\circ} 0^{\circ} \mathrm{C}$ dalam atmosfer udara yang diikuti proses hidrotermal pada suhu $100^{\circ} \mathrm{C}$ selama 12 jam. Hasil menunjukkan bahwa kristalinitas zeolit-A dengan pemisahan $\mathrm{Fe}$ dan $\mathrm{Ca}$ sebesar $88,64 \%$ dengan tingkat kemurnian yang lebih besar, sementara pada zeolit-A tanpa pemisahan $\mathrm{Fe}$ dan $\mathrm{Ca}$ yang telah dilaporkan pada penelitian sebelumnya didapatkan kristalinitas sebesar $\mathbf{8 4 , 1 9 \%}$ dengan tingkat kemurnian yang lebih rendah.
\end{abstract}

Kata Kunci-Zeolit-A; Abu Dasar; Sintesis; Pemisahan Fe dan Ca; Peleburan.

\section{PENDAhuluan}

A bu dasar batubara merupakan salah satu jenis residu yang dihasilkan oleh pembakaran batubara PLTU yang jatuh pada dasar tungku pembakar (boiler) dan terkumpul pada penampung debu (ash hopper) karena terlalu berat untuk dibawa oleh gas buang [1]. Menurut peraturan pemerintah No. 18 tahun 1999, limbah abu dasar digolongkan sebagai limbah B3 (bahan beracun dan berbahaya). Oleh karena itu, untuk mengurangi dampak negatif dari limbah abu tersebut, sangat perlu dilakukan pemanfaatan limbah abu tersebut menjadi material yang memiliki nilai manfaat yang cukup tinggi [2]. Abu dasar batubara mengandung silikon (Si) 24,10 $\%$, aluminium (Al) $6,80 \%$, besi $(\mathrm{Fe}) 33,59 \%$, kalsium (Ca) 26,30\% dan karbon (C) total sekitar $11,2 \%$ berat. Kandungan Si dan Al dalam abu dasar ditemukan dalam fasa amorf dan kristalin [3]. Unsur-unsur kimia tersebut merupakan komponen penyusun zeolit, sehingga dengan proses tertentu, maka abu dasar dapat dimanfaatkan sebagai bahan penyusun zeolit atau mesoporous aluminosilikat lainnya [4].

Pembuatan zeolit dari abu dasar telah banyak dilaporkan. Berbagai jenis zeolit yang disintesis dari abu dasar diantaranya adalah zeolit-A [5], zeolit-X [6] dan hidroksi-sodalit [7]. Kandungan $\mathrm{SiO}_{2}$ dan $\mathrm{Al}_{2} \mathrm{O}_{3}$ pada abu dasar merupakan komponen utama dalam pembentukan zeolit yang dapat diekstrak melalui proses peleburan secara langsung [8]. Namun, peleburan secara langsung mengakibatkan rendahnya kemurnian dari zeolit yang terbentuk, karena beberapa pengotor abu dasar seperti Fe dan $\mathrm{Ca}$ juga ikut larut dalam ekstrak tersebut. Pengotor $\mathrm{Fe}$ dan $\mathrm{Ca}$ yang terlarut tersebut mengakibatkan terbentuknya fasa lain seperti hidroksi sodalit, sehingga penghilangan logam $\mathrm{Fe}$ dan $\mathrm{Ca}$ dapat mempengaruhi pembentukan kristal zeolit yang terbentuk [8]. Oleh karena itu, kandungan $\mathrm{Fe}$ dan $\mathrm{Ca}$ pada abu dasar perlu dilakukan pemisahan, sehingga dapat digunakan untuk sintesis zeolit.

\section{URAIAN PENELITIAN}

\section{A. Alat dan bahan}

Alat yang digunakan adalah corong Buchner, muffle furnace, dan reaktor hidrotermal (autoclave stainless steel). Karakterisasi material ini dilakukan menggunakan X-Ray Flourescence (XRF), X-Ray Diffraction (XRD) dan Scanning Electron Microscopy (SEM).

Bahan yang digunakan adalah abu dasar batubara, air demineralisasi, padatan natrium aluminat (Sigma Aldrich), larutan natrium silikat (Sigma Aldrich) dan pelet $\mathrm{NaOH}(99 \%$ p.a).

\section{B. Prosedur Kerja}

\section{1) Identifikasi Komposisi Kimia Abu Dasar}

Abu dasar batubara dipanaskan pada suhu $110^{\circ} \mathrm{C}$ selama 3 jam untuk menghilangkan kandungan air yang terdapat dalam abu dasar tersebut. Selanjutnya abu dasar dianalisa menggunakan $X$-ray Flourescence (XRF) untuk menentukan komposisi unsur-unsur dari abu dasar.

2) Pemisahan Fe dan Ca Abu Dasar Batubara

Pemisahan kandungan besi (Fe) pada abu dasar batubara pada penelitian ini dilakukan menggunakan magnet ferrit dan larutan $\mathrm{HCl} 12 \mathrm{M}$ [9]. Abu dasar diletakkan dalam bejana yang cukup luas, kemudian magnet ferrit diletakkan pada bagian atas abu dasar. Abu dasar harus diaduk terus menerus agar proses pemisahan kadar Fe dapat merata pada seluruh bagian abu dasar. Kemudian, Abu dasar bebas Fe ditimbang sebesar 5 gram dan dimasukkan dalam larutan $\mathrm{HCl} 12 \mathrm{M}$ sebanyak 150 ml. Campuran tersebut kemudian diaduk selama 4 jam pada suhu $100^{\circ}-110^{\circ} \mathrm{C}$ untuk memaksimalkan proses pemisahan. Campuran dikeringkan pada suhu $105^{\circ} \mathrm{C}$. Hasil pemisahan kemudian dikarakterisasi kembali menggunakan $X$-ray Flourescence (XRF) dan X-Ray Diffraction (XRD) untuk menentukan komposisi unsurunsur kimianya, serta fasa mineral dari abu dasar setelah pemisahan.

3) Peleburan Abu dasar dan Ekstraksi Si dan Al

Abu dasar batubara dan $\mathrm{NaOH}$ yang sudah digerus, dicampurkan dengan perbandingan massa $\mathrm{NaOH} / \mathrm{Abu}$ dasar $=1,2$. Campuran kemudian dipanaskan pada suhu $750^{\circ} \mathrm{C}$ dalam waktu tertentu dalam muffle furnace. Setelah peleburan campuran didinginkan, digerus dan dibuat suspensi dengan penambahan air demineralisasi, campuran hasil peleburan diaduk dan dilakukan pemeraman (aging) selama 2 jam pada suhu kamar. Campuran yang telah diperam, selanjutnya disaring dan diambil ekstrak supernatannya sebagai larutan sumber Si dan Al [10]. 


\section{4) Sintesis Zeolit-A dari Abu Dasar}

Ekstrak tersebut kemudian dibuat slurry berkomposisi molar relatif $\mathrm{Al}_{2} \mathrm{O}_{3}: 1,926 \mathrm{SiO}_{2}$ dengan penambahan larutan $\mathrm{NaAlO}_{2}-\mathrm{NaOH}$ sebagai sumber $\mathrm{Al}$ untuk mengatur rasio molar $\mathrm{Si} / \mathrm{Al}$ yang sesuai untuk sintesis zeolit Na-A. Kemudian kristalisasi hidrotermal dilakukan pada suhu $100^{\circ} \mathrm{C}$ selama 12 jam. Setelah perlakuan hidrotermal, padatan hasil kristalisasi dipisahkan dari filtratnya, dicuci dengan air demineralisasi sampai $\mathrm{pH}$ 910, dan dikeringkan pada suhu $105^{\circ} \mathrm{C}$ selama 24 jam [3].

5) Karakterisasi Zeolit-A dari Abu Dasar

Zeolit-A hasil sintesis dikarakterisasi menggunakan $X$ Ray Difraction (XRD), X-Ray Flourescence (XRF) dan Scanning Electron Microscope (SEM).

\section{HASIL DAN PEMBAHASAN}

\section{A. Identifikasi Komposisi Kimia Abu Dasar}

Penelitian ini diawali dengan penentuan komposisi kimia dari abu dasar dengan menggunakan Instrumen $X$ Ray Flourescence (XRF). Penentuan komposisi kimia yang terkandung dalam abu dasar sangat penting karena dapat diketahui prosentase kandungan berat $\mathrm{Si}$ dan $\mathrm{Al}$ dalam abu dasar yang merupakan komponen utama dalam pembuatan zeolit. Hasil analisa abu dasar dengan $X$-Ray Flourescence (XRF) dapat ditunjukkan pada Tabel 1.

\begin{tabular}{cc|cc}
\multicolumn{3}{c}{ TABEL 1. HASIL ANALISIS KOMPOSISI KIMIA ABU DASAR } \\
\hline \hline Komponen & $\begin{array}{c}\text { Komponen } \\
\text { (\% berat) }\end{array}$ & Komponen & $\begin{array}{c}\text { Komponen } \\
\text { (\% berat) }\end{array}$ \\
\hline $\mathrm{Al}$ & 5,5 & $\mathrm{Fe}$ & 49,40 \\
$\mathrm{Si}$ & 13,2 & $\mathrm{Ni}$ & 0,23 \\
$\mathrm{~S}$ & 0,59 & $\mathrm{Cu}$ & 0,14 \\
$\mathrm{~K}$ & 1,2 & $\mathrm{Zn}$ & 0,22 \\
$\mathrm{Ca}$ & 25,5 & $\mathrm{Sr}$ & 0,53 \\
\hline \hline
\end{tabular}

Berdasarkan hasil analisa menggunakan X-Ray Flourescence (XRF) tersebut, abu dasar memiliki kandungan $\mathrm{Si}$ dan $\mathrm{Al}$ dalam bentuk oksidanya yang cukup tinggi yaitu $13,2 \%$ dan 5,5\%. Adanya kandungan Si dan Al tersebut membuat abu dasar dapat dijadikan sebagai bahan dalam pembuatan zeolit. Nilai kandungan $\mathrm{Si}$ dan $\mathrm{Al}$ tersebut digunakan dalam menentukan rasio Si/Al. Nilai rasio tersebut akan mempengaruhi jenis zeolit yang terbentuk. Nilai rasio berat $\mathrm{Si} / \mathrm{Al}$ pada abu dasar tersebut adalah sebesar 2,4. Nilai rasio Si/Al tersebut relatif rendah, sehingga sesuai digunakan sebagai bahan dasar untuk mensintesis zeolit dengan nilai Si rendah seperti Zeolit-A.

Selain Si dan Al, kandungan yang mendominasi dalam abu dasar adalah $\mathrm{Fe}$ dan $\mathrm{Ca}$. Adanya kandungan $\mathrm{Ca}$ dan Fe cukup tinggi dapat mengganggu dalam proses sintesis zeolit, sehingga $\mathrm{Ca}$ dan $\mathrm{Fe}$ harus dipisahkan terlebih dahulu. Hasil pemisahan, dilakukan analisa kembali menggunakan X-Ray Flourescence (XRF) untuk menentukan nilai kandungan $\mathrm{Ca}$ dan Fe setelah proses pemisahan. Hasil analisa tersebut ditunjukkan pada Tabel 2.

TABEl 2. Hasil ANAlisis Komposisi Kimia ABU DaSAR SETElaH PEMISAHAN FE DAN CA

\begin{tabular}{cccc}
\hline \hline Komponen & $\begin{array}{c}\text { Komponen } \\
\text { (\% berat) }\end{array}$ & Komponen & $\begin{array}{c}\text { Komponen } \\
\text { (\% berat })\end{array}$ \\
\hline $\mathrm{Al}$ & 3,2 & $\mathrm{Fe}$ & 23,50 \\
$\mathrm{Si}$ & 37,1 & $\mathrm{Ni}$ & 1,46 \\
$\mathrm{~S}$ & 0,59 & $\mathrm{Cu}$ & 0,17 \\
$\mathrm{~K}$ & 2,0 & $\mathrm{Zn}$ & 0,24
\end{tabular}
$\mathrm{Ca}$
11,1
$\mathrm{Sr}$
0,50

Pada Tabel 2 tersebut, dapat terlihat bahwa proses pemisahan Fe dan $\mathrm{Ca}$ mampu menurunkan kandungan $\mathrm{Fe}$ pada abu dasar sebesar $25,90 \%$ dan kandungan $\mathrm{Ca}$ sebesar 14,40\%. Penurunan komposisi tersebut menunjukkan bahwa $\mathrm{Ca}$ dalam fasa kalsit $\left(\mathrm{CaCO}_{3}\right)$ dan kalsium oksida $(\mathrm{CaO})$ telah bereaksi dengan $\mathrm{HCl}$ membentuk $\mathrm{CaCl}_{2}$ yang mudah larut dalam air. Kandungan $\mathrm{Fe}$ yang masih tersisa dalam abu dasar juga ikut bereaksi dengan larutan $\mathrm{HCl}$ membentuk $\mathrm{FeCl}_{3}$. Reaksi pemisahan logam-logam oksida pada abu dasar tersebut dapat dilihat pada Persamaan (1-3).

$$
\begin{aligned}
& \mathrm{CaCO}_{3}(\mathrm{~s})+2 \mathrm{HCl}(\mathrm{aq}) \rightarrow \mathrm{CaCl}_{2}(\mathrm{aq})+\mathrm{CO}_{2}(\mathrm{~g})+\mathrm{H}_{2} \mathrm{O} \\
& \mathrm{CaO}(\mathrm{s})+\mathrm{HCl}(\mathrm{aq}) \rightarrow \mathrm{CaCl}_{2}(\mathrm{aq})+\mathrm{H}_{2} \mathrm{O}(\mathrm{l})[11] \\
& \mathrm{Fe}_{2} \mathrm{O}_{3}(\mathrm{~s})+\mathrm{HCl}(\mathrm{aq}) \rightarrow 2 \mathrm{FeCl}_{3}(\mathrm{aq})+3 \mathrm{H}_{2} \mathrm{O}(\mathrm{l})[12]
\end{aligned}
$$

\section{B. Peleburan Abu Dasar dan Esktraksi Si dan Al}

Proses ekstraksi Si dan Al dalam abu dasar dalam pembuatan zeolit dapat dilakukan dengan peleburan dalam atmosfer udara [3]. Peleburan abu dasar dengan atmosfer udara akan menghasilkan padatan berwarna kuning kecoklatan yang menandakan bahwa kandungan karbon dalam abu dasar telah hilang selama proses peleburan berlangsung, sehingga didapatkan hasil leburan bebas karbon. Kandungan karbon dalam abu dasar akan mudah lepas dan membentuk hasil samping berupa gas $\mathrm{CO}_{2}$, sehingga dari proses inilah akan dihasilkan zeolit-A dengan kemurnian tinggi tanpa adanya karbon.

Padatan leburan kemudian dilakukan karakterisasi menggunakan XRD untuk menentukan komponen mineral yang terbentuk yang hasilnya ditunjukkan pada Gambar 1 .

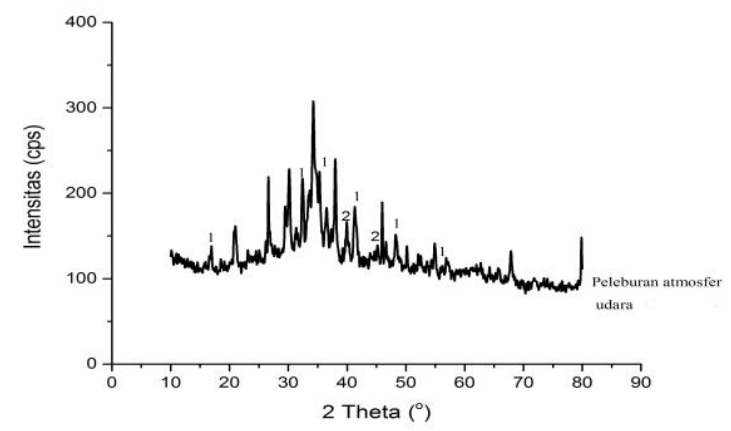

Gambar 1. Difraktogram padatan abu dasar hasil leburan (1=Natrium Silikat, 2= Natrium AluminatSilikat).

Pada difraktogram tersebut, menunjukkan bahwa proses peleburan akan menghasilkan garam natrium silikat dan natrium alumina silikat dengan adanya pola puncak-puncak khas yang menunjukkan puncak difraksi dari kedua garam tersebut. Hasil difraktogram tersebut juga menunjukkan hilangnya puncak-puncak dari hematit dan kalsit. Hal ini dikarenakan proses peleburan pada suhu tinggi membuat hematit dan kalsit akan hilang. Selain itu, puncak-puncak fasa kristalin lainnya seperti kuarsa dan mullit sebagian besar juga ikut menghilang yang menunjukkan bahwa kuarsa dan mullit tersebut telah bereaksi dengan $\mathrm{NaOH}$ dan diaktivasi menghasilkan garam natrium silikat (PDF 16-0818) dan garam alumina silikat (PDF 33-1203). Selain fasa kristalin tersebut, fasa amorf dari aluminasilikat juga ditemukan dalam intensitas yang lebih banyak jika dibandingkan pada abu dasar sebelum dilakukan 
peleburan. Hal ini membuktikan bahwa proses peleburan pada suhu tinggi merupakan metode yang efektif dalam mengekstrak kandungan $\mathrm{Si}$ dan $\mathrm{Al}$ dalam abu dasar menjadi garam yang mudah larut.

Setelah didapatkan hasil berupa natrium silikat dan natrium aluminasilikat dari proses peleburan, kemudian dilakukan proses ekstraksi dari padatan hasil leburan untuk mendapatkan komponen Si dan Al yang terlarut. Proses ekstraksi pada penelitian ini dilakukan dengan mencampurkan padatan hasil leburan yang telah digerus dengan air demineralisasi. Reaksi padatan hasil peleburan abu dasar dalam air destilasi adalah sebagai berikut :

$$
\begin{aligned}
& \mathrm{Na}_{2} \mathrm{SiO}_{3(\mathrm{~s})}+\mathrm{H}_{2} \mathrm{O}_{(\mathrm{aq})} \rightarrow \mathrm{Na}_{2} \mathrm{SiO}_{3(\mathrm{aq})} \\
& \mathrm{Na}_{2} \mathrm{AlSiO}_{4(\mathrm{~s})}+\mathrm{H}_{2} \mathrm{O}_{(\mathrm{aq})} \rightarrow \mathrm{Na}_{2} \mathrm{Al}(\mathrm{OH})_{4(\mathrm{aq})}
\end{aligned}
$$

Setelah dilakukan pemeraman, campuran tersebut disaring dan dihasilkan filtrat rata-rata sebesar $200 \mathrm{ml}$. Hasil filtrat ini tidak sama dengan volume awal air demineralisasi yang dimasukkan untuk proses ekstraksi, karena sejumlah air demineralisasi tersebut terserap pada padatan hasil leburan.

Ekstrak leburan tersebut kemudian digunakan sebagai bahan pembuatan gel. Nilai rasio $\mathrm{SiO}_{2} / \mathrm{Al}_{2} \mathrm{O}_{3}$ dikontrol melalui penambahan larutan $\mathrm{NaAlO}_{2}-\mathrm{NaOH}$ sebagai sumber Al eksternal, karena nilai kelarutan Al dalam ekstrak cukup kecil. Penambahan sumber Al tersebut bertujuan untuk memperkecil nilai rasio molar gel. Besarnya rasio molar dalam penelitian ini diatur sesuai rasio molar gel zeolit-A yaitu $\mathrm{SiO}_{2} / \mathrm{Al}_{2} \mathrm{O}_{3}$ sebesar 1,926. Perbandingan molar $\mathrm{SiO}_{2} / \mathrm{Al}_{2} \mathrm{O}_{3}$ itulah yang paling menentukan terbentuknya zeolit-A [5].

Penambahan larutan $\mathrm{NaAlO}_{2}-\mathrm{NaOH}$ tersebut akan menghasilkan pasta aluminosilikat. Residu ekstrak leburan dalam atmosfer udara, tidak perlu ditambahkan residu hasil ekstrak dalam preparasi sintesis zeolit agar nantinya dihasilkan zeolit tanpa karbon. Pasta aluminosilikat yang terbentuk memiliki karakteristik berbentuk gel berwarna putih layaknya mensintesis zeolit-A dari bahan murni. Ion aluminat dan ion silikat akan mengalami kondensasi dalam proses pembentukan pasta aluminosilikat tersebut dan digunakan sebagai prekursor pembuatan zeolit.

\section{Sintesis Zeolit-A dari Abu Dasar}

Zeolit-A dalam penelitian ini disintesis dari dua jenis prekursor yaitu dari bahan murni/sintetik dan abu dasar. Sintesis zeolit-A dengan bahan murni dalam penelitian ini digunakan sebagai pembanding terhadap zeolit-A yang disintesis dari abu dasar. Proses sintesis zeolit-A dengan bahan murni dilakukan sesuai komposisi dengan perbandingan komposisi molar 3,165 $\mathrm{Na}_{2} \mathrm{O}: 1 \mathrm{Al}_{2} \mathrm{O}_{3}$ : 1,926 $\mathrm{SiO}_{2}$ : $128 \mathrm{H}_{2}$ O. [13]. Prekursor yang digunakan adalah air demineralisasi (DM), $\mathrm{NaAlO}_{2}, \mathrm{Na}_{2} \mathrm{SiO}_{3}$, dan $\mathrm{NaOH}$. Larutan prekursor diaduk dengan kecepatan konstan selama 12 jam untuk proses homogenisasi. Kemudian larutan aluminosilikat yang terbentuk dimasukkan, ke dalam autoklaf untuk proses hidrotermal dan proses kristalisasi selama 12 jam pada suhu $100^{\circ} \mathrm{C}$. Reaksi yang terjadi selama proses kristalisasi pada sintesis zeolit A ditunjukkan oleh Persamaan (6-8) [14].

$\mathrm{Na}_{2} \mathrm{SiO}_{3(\mathrm{~s})}+3 \mathrm{H}_{2} \mathrm{O}(\mathrm{l}) \rightarrow \mathrm{Na}_{2} \mathrm{SiO}_{3(\mathrm{aq})}$

$\mathrm{NaAlO}_{2(\mathrm{~s})}+2 \mathrm{H}_{2} \mathrm{O}(\mathrm{l}) \rightarrow \mathrm{NaAl}(\mathrm{OH})_{4(\mathrm{aq})}$

$\mathrm{NaOH}_{(\mathrm{aq})}+\mathrm{Na}_{2} \mathrm{SiO}_{3}(\mathrm{aq})+\mathrm{NaAl}(\mathrm{OH})_{4(\mathrm{aq})} \stackrel{\text { Suhu kamar }}{\longrightarrow}$
$\left[\mathrm{Na}_{\mathrm{x}}\left(\mathrm{AlO}_{2}\right)_{\mathrm{y}}\left(\mathrm{SiO}_{2}\right)_{\mathrm{z}} \cdot \mathrm{NaOH} \cdot \mathrm{H}_{2} \mathrm{O}\right]_{(\mathrm{gel})} \stackrel{100^{\circ} \mathrm{C}}{\longrightarrow}$

$\mathrm{Na}_{12}\left[\left(\mathrm{SiO}_{2}\right)_{12}\left(\mathrm{AlO}_{2}\right)_{12}\right] .27 \mathrm{H}_{2} \mathrm{O}$ (Kristal zeolit-A)

Hasil proses hidrotermal berupa padatan putih dan larutan supernatan yang berwarna bening. Padatan disaring untuk memisahkan dengan larutan dan dilakukan pencucian dengan air demineralisasi hingga pH kurang dari 9. Perlakuan pencucian dilakukan untuk menghilangkan sisa $\mathrm{NaOH}$ yang bersifat basa. Nilai derajat keasaman padatan zeolit A hasil proses hidrotermal adalah 14 yang mengindikasikan bahwa zeolit-A telah terbentuk karena prekursor utama yakni $\mathrm{Al}(\mathrm{OH})_{4}^{-}$terbentuk pada $\mathrm{pH}>6$ [15]. Tahapan selanjutnya adalah pengeringan padatan di dalam oven pada suhu $100^{\circ} \mathrm{C}$ selama 12 jam untuk menghilangkan air yang masih terikat pada padatan zeolit hasil sintesis, sehingga diperoleh padatan zeolit-A berwarna putih.

Sementara itu, proses pembentukan zeolit dari prekursor peleburan abu dasar dilakukan melalui metode hidrotermal dalam autoklaf stainless steel pada kondisi suhu $100^{\circ} \mathrm{C}$ selama $12 \mathrm{jam}$. Pemilihan waktu hidrotermal tersebut karena zeolit-A dengan kristalinitas tinggi dari bahan alam berupa ekstrak abu layang dapat disintesis dengan waktu hidrotermal selama 12 jam dalam suhu $100^{\circ} \mathrm{C}$ [5]. Pada akhir proses hidrotermal, didapatkan padatan hasil sintesis berwarna putih dengan filtrat berwarna kuning. Padatan yang dihasilkan kemudian disaring dan dicuci berulang kali dengan air demineralisasi untuk menghilangkan pengotor dan kelebihan $\mathrm{NaOH}$ yang masih menempel hingga didapatkan $\mathrm{pH}$ 9-10. Padatan yang telah dicuci kemudian dikeringkan dalam oven pada suhu $105^{\circ} \mathrm{C}$ selama 24 jam untuk menghilangkan kelebihan air yang terikat pada padatan hasil sintesis.

Padatan hasil sintesis pada perlakuan hidrotermal dari dikarakterisasi menggunakan XRD untuk mengetahui struktur kristal zeolit yang terbentuk. Hasil analisa menggunakan XRD dapat ditunjukkan pada Gambar 2. Hasil difraktogram tersebut menunjukkan bahwa zeolit-A dengan pemisahan $\mathrm{Fe}$ dan $\mathrm{Ca}$ memiliki pola difraksi dari zeolit-A. Pola difraksi tersebut memiliki pola yang sama dengan zeolit-A tanpa pemisahan $\mathrm{Fe}$ dan $\mathrm{Ca}$ yang pernah dilaporkan pada penelitian sebelumnya [3]. Zeolit-A dengan pemisahan $\mathrm{Fe}$ dan $\mathrm{Ca}$ memiliki nilai kristalinitas tertinggi yaitu sebesar $88,64 \%$ sementara untuk zeolit-A tanpa pemisahan $\mathrm{Fe}$ dan $\mathrm{Ca}$ memiliki nilai kristalinits lebih rendah yaitu $84,19 \%$.

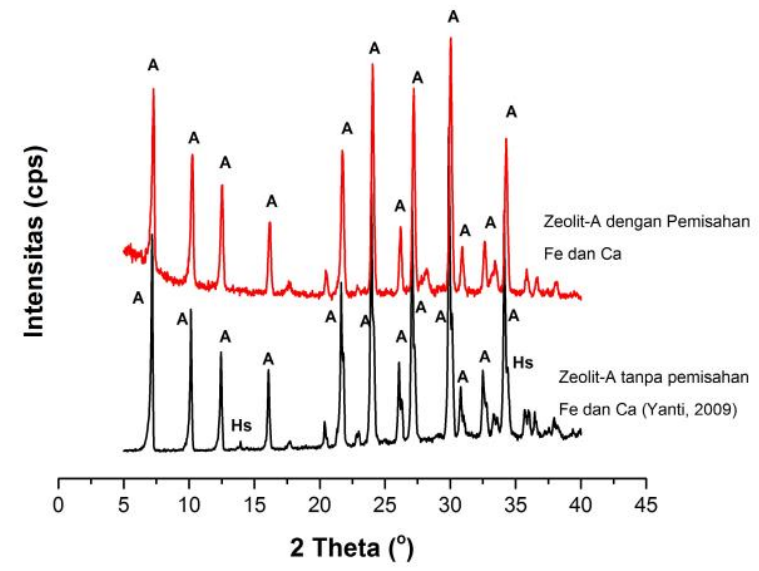

Gambar 2. Difraktogram Zeolit-A tanpa pemisahan Fe dan Ca [3] dan Zeolit-A hasil sintesis dengan pemisahan $\mathrm{Fe}$ dan $\mathrm{Ca}$ 
Zeolit-A yang terbentuk merupakan tipe zeolit Linde Tipe-A (LTA) dengan rumus $\left[\mathrm{Na}_{96}\left(\mathrm{AlO}_{2}\right)_{96}\left(\mathrm{SiO}_{2}\right)_{96} .216 \mathrm{H}_{2} \mathrm{O}\right]$. Kristalinitas yang tinggi menunjukkan bahwa zeolit-A yang dihasilkan memiliki kemurnian yang tinggi jika dibandingkan oleh zeolit-A yang disintesis tanpa pemisahan Fe dan Ca. Kemurnian tersebut dapat diamati pada pengujian menggunakan SEM yang dapat ditunjukkan pada Gambar 3 .

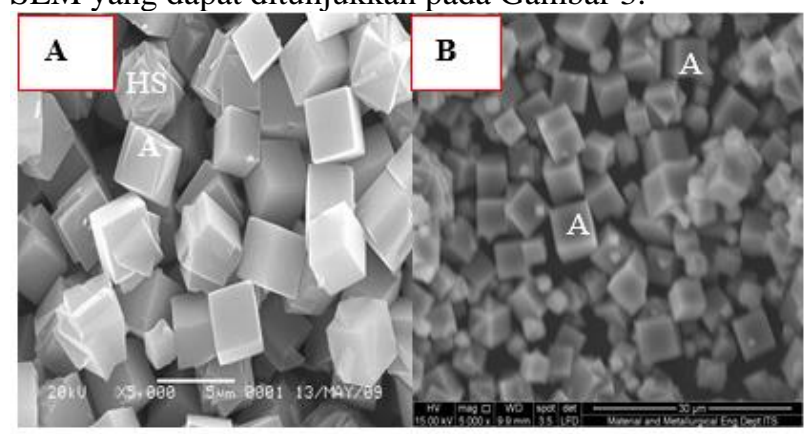

Gambar 3. Hasil Foto SEM (a) Zeolit-A tanpa pemisahan Fe dan Ca [3] (b) Zeolit-A dengan pemisahan Fe dan $\mathrm{Ca}$ (A=Zeolit-A, HS=Hidroksi Sodalit)

Zeolit yang disintesis melalui proses pemisahan $\mathrm{Fe}$ dan $\mathrm{Ca}$ memiliki bentuk kubik. Bentuk ini sama halnya dengan zeolit yang disintesis dari abu dasar pada penelitian sebelumnya, namun tanpa dilakukan pemisahan kandungan $\mathrm{Fe}$ dan $\mathrm{Ca}$ yang juga memiliki bentuk kubik [3]. Dari hasil SEM tersebut, juga dapat terlihat bahwa zeolit-A dengan pemisahan $\mathrm{Fe}$ dan $\mathrm{Ca}$ menghasilkan fasa kristal dengan struktur geometri kubik yang teratur serta tidak adanya fasa lain seperti hidroksi sodalit yang terbentuk seperti halnya proses sintesis zeolit dari abu dasar yang pernah dilaporkan oleh beberapa penelitian sebelumnya [3], [8], sehingga kemurnian zeolit-A yang terbentuk cukup tinggi. Tingginya kemurnian tersebut memberikan indikasi bahwa selama proses sintesis, ekstrak leburan tidak mengandung komponen-komponen pengganggu, sehingga proses pembentukan zeolit terjadi secara sempurna. Hal tersebut terjadi karena komponen pengganggu seperti $\mathrm{Fe}$ dan $\mathrm{Ca}$ pada abu dasar telah berhasil dipisahkan walaupun tidak $100 \%$ semua komponen $\mathrm{Fe}$ dan $\mathrm{Ca}$ berhasil dihilangkan dari abu dasar. Namun, dengan kadar $\mathrm{Fe}$ dan $\mathrm{Ca}$ yang rendah, hal itu sangat berpengaruh terhadap karakteristik zeolit-A yang terbentuk.

\section{KESIMPULAN}

Zeolit-A dari abu dasar dapat disintesis dengan pemisahan kadar $\mathrm{Fe}$ dan $\mathrm{Ca}$ sebelum dilakukan proses peleburan. Hasil zeolit-A yang terbentuk menunjukkan bahwa proses pemisahan Fe dan Ca pada abu dasar dapat meningkatkan kristalinitas dan kemurnian pada zeolit-A tersebut.

\section{UCAPAN TERIMA KASIH}

Penulis menyampaikan terima kasih kepada Laboratorium Energi ITS dan Laboratorium Kimia UNJ atas bantuan karakterisasinya, kedua orang tua dan semua pihak yang telah membantu dalam penelitian ini.

\section{DAFTAR PUSTAKA}

[1] Prijatama, H. dan Sumarnadi, E.T., 1996. "Mengubah Limbah menjadi Rupiah: Pemanfaatan limbah Abu Batubara PLTU". Prosiding Pemaparan Hasil Litbang Ilmu Pengetahuan Teknik, Bandung.

[2] Kementerian Lingkungan Hidup. 2006. "Pengelolaan Bahan dan Limbah Berbahaya dan Beracun". www.LingkunganHidup.com

[3] Yanti, Y. 2009. "Sintesis Zeolit A dan Zeolit Karbon Aktif dari Abu Dasar PLTU Paiton dengan Metode Peleburan". Tesis Megister, Institut Teknologi Sepuluh Nopember, Surabaya.

[4] Tanaka, H. 2002. 'Formation of Na-A and Na-X Zeolites from waste solution in conversion of aol fly ash to zeolites". Material Research Buletin, 37, hal 1873-1884.

[5] Said, N.F, Nurul, W. 2008. "Adsorpsi Cu(II) pada Zeolit A yang Disintesis dari Abu Dasar Batubara PT IPMOMI PAITON". Jurnal Zeolit Indonesia, 7, hal 1-11.

[6] Nurul, H.Z.M. 2012. "Sintesis Zeolit-X dari Abu Dasar Batubara dan Karakterisasinya sebagai Material Penyimpan Hidrogen". Skripsi, Institut Teknologi Sepuluh Nopember, Surabaya.

[7] Buhl, J.C., Gesing, T.M., Kerkamm, I., Gurris, C. 2003. "Synthesis and Crystal Structure of Cyanate Sodalite $\mathrm{Na}_{8}(\mathrm{OCN})_{2}\left[\mathrm{Al}_{6} \mathrm{Si}_{6} \mathrm{O}_{24}\right]$ ". Microporous and Mesoporous Materials, 65 , hal $145-153$

[8] Sallam, M. 2006. "Zeolite Synthesis from Municipial Solid Waste Ash using Fusion and Hydrothermal Treatment". Graduate Theses and Dissertation, Universitas South Florida.

[9] Chareonpanich, M., Jullaphan, O., Tang, C. 2011. "Bench-Scale Synthesis Zeolite-A from Subbituminus Coal Ashes with High Crystalline Content". Journal of Cleaner Production, 19, hal 5863.

[10] Londar, E., Hamzah, F., Nurul, W. 2010.” Pengaruh Karbon Terhadap Pembentukan Zeolit dari Abu Dasar dengan Metode Hidrotermal langsung”. Jurnal Kimia ITS, FMIPA ITS, hal 1- 13.

[11] Wolf, K.J., Smeda, A., Muller, M., Hilpert, K. 2005. "Investigations on the Influence of Additives for SO2 Reduction during High Alkaline Biomass Combustion”. Energy Fuels, 19, hal 820-824.

[12] Tobiasen, L., Skytte, R., Pedersen, LS, Pedersen, S.T., Linberg, M.A. 2007. "Deposit Characteristic After Injection of Additive to A Danish Straw-Fired Suspension Boiler". Fuel Process Technological, 88, hal 1108-1117.

[13] Kugbe, J., Matsue, N., dan Henmi, T. (2009). "Synthesis of Linde type A zeolite-goethite nanocomposite as an adsorbent for cationic and anionic pollutants". Journal of Hazardous Materials, 164, hal. 929-935.

[14] Ojha, K., Pranadhan, N.C, Samanta, A.N. 2004. "Zeolite from Fly Ash : Synthesis and Characterization". Departement of Chemical Engineering, Indian of Technology, 21, hal 555-564.

[15] Handayani, R.F. (2012). "Sintesis ZSM-5 Menggunakan Prekursor Zeolit Nano Kluster: Pengaruh Waktu Hidrotermal". Proseding Skripsi, Surabaya, KIMIA ITS. 